\title{
Struktur dan Komposisi Hutan di Kawasan Karst Temeang
}

\author{
Arbain $^{1}$, Sugiarto ${ }^{2}$, dan Titis Hutama Syah ${ }^{3}$ \\ 1,2,3 Sekolah Tinggi Pertanian Kutai Timur, Sangatta, Kutai Timur, Kalimantan Timur. \\ 1 Email: arbain2002@gmail.com \\ 2 Email: sugiarto@stiperkutim.ac.id \\ ${ }^{3}$ Email: titis@stiperkutim.ac.id
}

\begin{abstract}
This study aimed at determining the structure and composition of vegetation in the Temeang karst forest area, Karangan District, East Kutai Regency. The method used was making a measuring plot with an area of 1 ha, which was divided into 25 plots, $20 \times 20 \mathrm{~m}$ each in size. The results showed that the highest importance, density, and frequency index was found in the Pterospermum javanicum. This species was an easy growing species that widely distributed. The highest dominance was of Shorea guiso, which had a large stem diameter. Canopy stratum was arranged in some layers, from bottom to top layer, consist of understorey to higher trees. The presence of open spaces in canopy showed that human intervention was needed to accelerate succession.

Keywords: Forest succesion, Karst Forest, Permanent plot, Temeang Karst Area, Vegetation Analysis,
\end{abstract}

ABSTRAK
Penelitian ini bertujuan untuk mengetahui struktur dan komposisi vegetasi di kawasan
hutan karst Temeang, Kecamatan Karangan, Kabupaten Kutai Timur. Metode yang
digunakan adalah membuat petak ukur dengan luas 1 ha, yang dibagi menjadi 25 petak
ukur berukuran 20x20m, Hasil penelitian menunjukkan bahwa Indeks Nilai penting,
Kerapatan, dan frekuensi tertinggi terdapat pada jenis Pterospermum javanicum. Jenis
tersebut merupakan jenis yang mudah tumbuh dengan sebaran yang luas. Dominansi
tertinggi terdapat pada jenis Shorea guiso, yang memiliki diameter batang yang besar-
besar. Strata tajuk tersusun berlapis, dari lapisan atas sampai lapisan bawah yang
terdiri dari tumbuhan bawah hingga pohon-pohon yang tinggi. Masih terdapatnya
bagian-bagian tajuk yang terbuka menunjukkan bahwa perlu adanya campur tangan
manusia untuk mempercepat suksesi.
Kata Kunci: Analisis Vegetasi, Hutan karst, Kawasan Karst Temeang, Petak Ukur Permanen, Suksesi hutan.

\section{Pendahuluan}

Karst menurut Haryono dan Adji (2017) adalah istilah yang berasal dari bahasa Slovenia yang memiliki makna lahan gersang berbatu. Meskipun pada mulanya istilah karst tidak digunakan untuk mendeskripsikan batu gamping dan proses pelarutan, namun istilah karst telah banyak digunakan untuk menyebut bentang lahan yang didominasi oleh hasil proses pelarutan batu gamping. Karst pada umumnya digunakan untuk menggambarkan kondisi kawasan yang berbatuan karbonat atau batuan lain yang memiliki sifat mudah larut (Cahyadi, 2017). Kawasan ini banyak terdapat di Indonesia, salah satunya terdapat di wilayah administratif Kabupaten Kutai Timur, Provinsi Kalimantan Timur. Kawasan tersebut merupakan wilayah karst seluas 1.187.225,28 ha (Susanto, 2016) yang dikenal oleh masyarakat setempat sebagai kawasan Temeang yang terletak di Kecamatan Karangan, Kabupaten Kutai Timur (Gambar 1). 


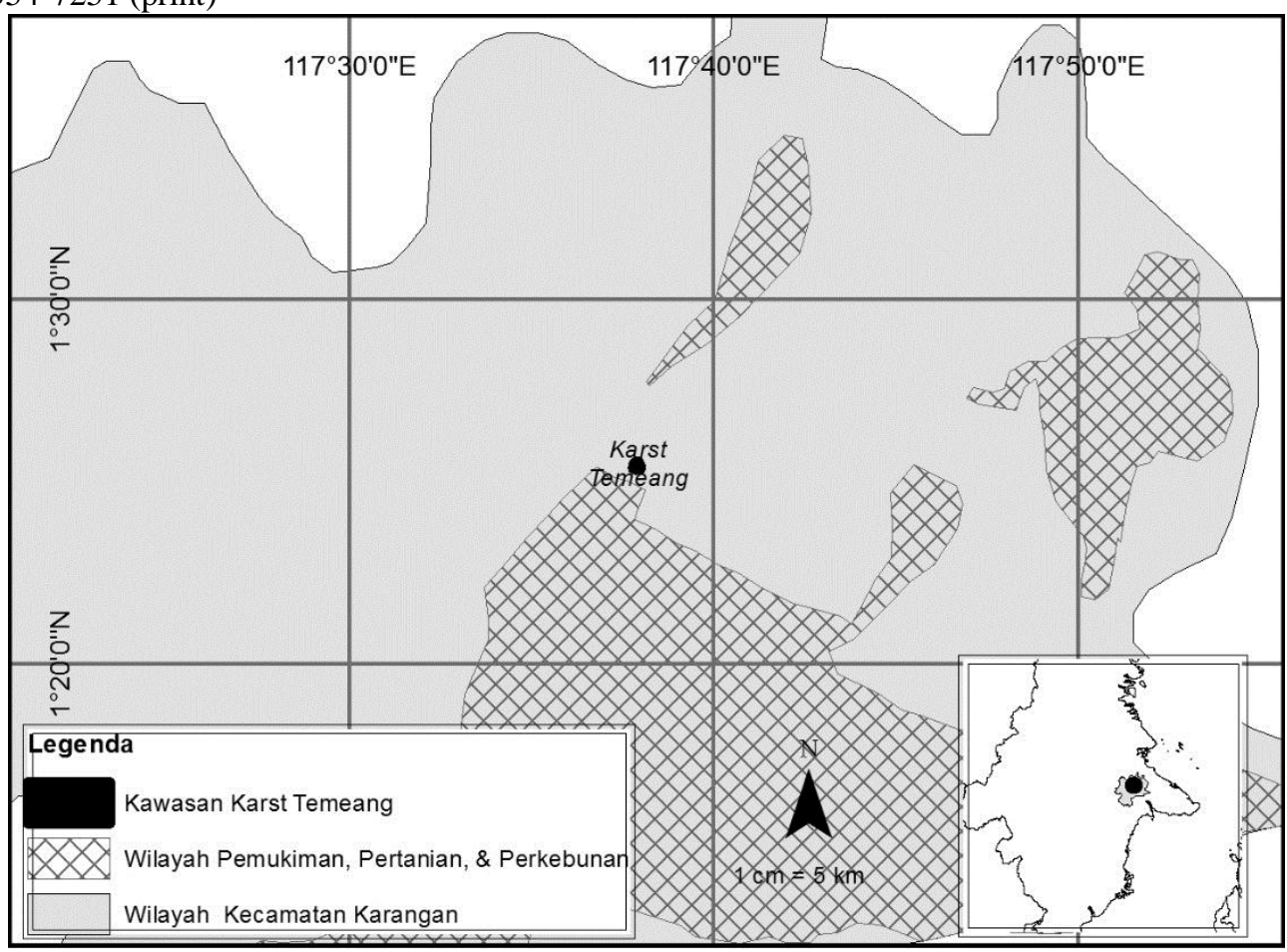

Gambar 1. Lokasi Karst Temeang

Kawasan Karst dicirikan dengan sumber daya lahan yang rendah (Adji \& Haryono, 2017). Jenis tanah yang berkembang di kawasan Karst pada umumnya bertekstur lempungan dengan kedalaman sedang yang dapat mendukung pertumbuhan pohon-pohon hutan dengan baik. Pada beberapa kawasan karst, masih dapat dijumpai hutan lebat. Hal ini dapat dijumpai di Kawasan Karst Temeang yang masih dijumpai adanya lingkungan karst dengan struktur hutan yang masih baik. Penelitian ini bermaksud untuk mengetahui kondisi aktual struktur dan komposisi pohon-pohon hutan yang terdapat pada kawasan tersebut. Dengan penelitian ini diharapkan dapat diperoleh gambaran yang sebenarnya tentang kondisi hutan pada kawasan tersebut, sehingga dapat dilakukan proyeksi pengelolaan pada masa mendatang.

\section{Metode penelitian}

Penelitian dilaksanakan pada kawasan karst Temeang di desa Karangan Hilir, Kecamatan Karangan, Kabupaten Kutai Timur, Provinsi Kalimantan Timur pada bulan Maret-April 2019. Penelitian ini mengambil petak ukur dengan luas 1 hektar yang dibagi menjadi 25 petak ukur dengan dengan ukuran $20 \times 20$ meter. Petak ukur ini digunakan untuk mengambil data pohon sesuai dengan pendapat Addelinetina dkk.(2019), yang dapat digunakan untuk mengukur tingkat keterbukaan tajuk. Pengamatan di dalam plot dilakukan bersamaan dengan pengukuran vegetasi untuk keperluan pembuatan diagram profil (vertikal dan horizontal) dengan contoh seperti yang terdapat pada Gambar 2. 

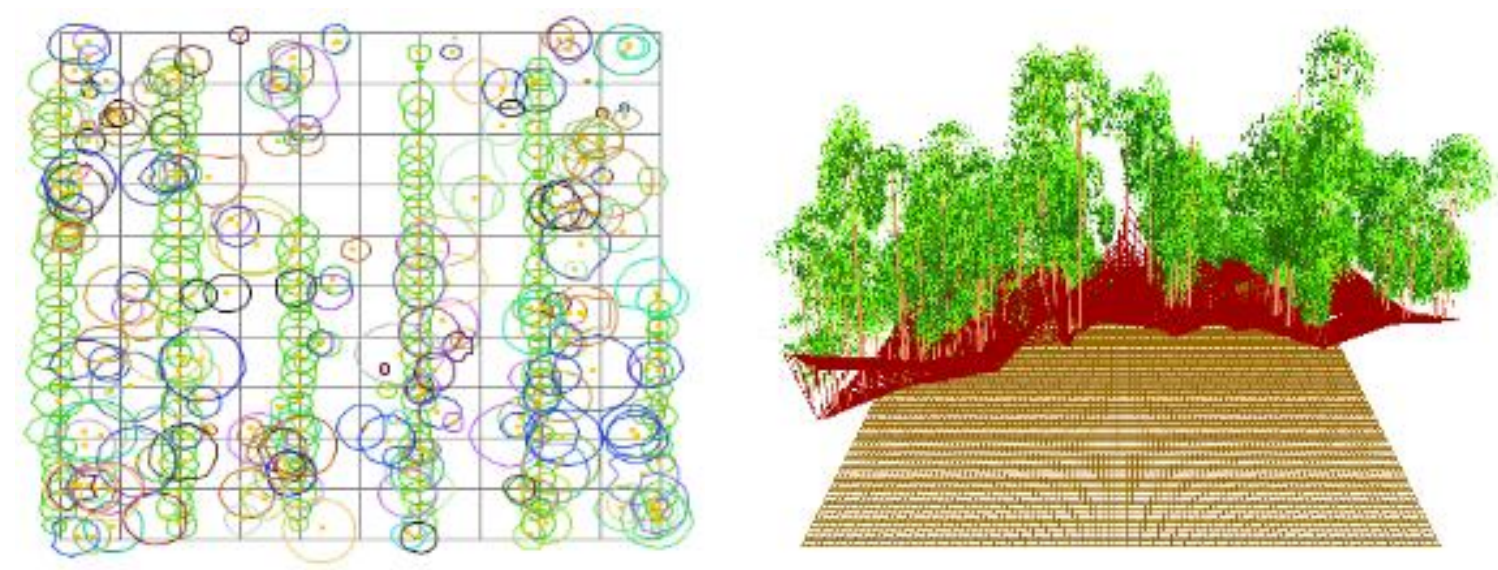

Sumber : Harja \& vincent (2008)

Gambar 2. Proyeksi horisontal (kiri) dan vertikal (kanan) tegakan

\section{Analisis Vegetasi}

Untuk menggambarkan struktur komunitas, analisis vegetasi yang digunakan adalah penghitungan Indeks Nilai Penting (Important Value Index), yang menggambarkan kerapatan pohon, penyebaran jenis (frekuensi), penguasaan jenis (dominansi) dan peran jenis (INP) (Muller-Dombois \& Ellenbeg, 1974). INP memberikan gambaran mengenai pengaruh atau peranan suatu jenis tumbuhan dalam komunitasnya. Indeks Nilai Penting (INP) dihitung dengan rumus):

Kerapatan jenis $A=$ Jumlah individu per satuan luas

Kerapatan relatif $(\mathrm{Kr})$ jenis $A=\frac{\text { Jumlah individu jenis } A}{\text { Jumlah individu semua jenis }} \times 100 \%$

Dominasi jenis $\mathrm{A}=$ jumlah luas bidang dasar jenis $\mathrm{A}$ per hektar

Dominansi relatif $(\mathrm{Dr})$ jenis $A=\frac{\text { Dominansi jenis } A}{\text { Jumlah dominansi jenis }} \times 100 \%$

Frekuensi jenis $A=\frac{\text { Jumlah petak ukur yang ditemukan jenis } A}{\text { Jumlah petak ukur semua jenis }} \times 100 \%$

Frekuensi relatif $(F r)$ jenis $A=\frac{\text { Frekuensi jenis } A}{\text { Jumlah frekuensi semua jenis }} \times 100 \%$

$I N P=K r$ jenis $A+\operatorname{Dr}$ jenis $A+F r$ jenis $A$ 
ISSN 2354-7251 (print)

\section{Profil tegakan}

Profil tegakan divisualisasikan dengan program Sexi-Fs versi 2.1.0 yang dikeluarkan oleh World Agroforestry Centre. Sexi-Fs merupakan suatu program yang didesain untuk menggambarkan proyeksi vertical dan horizontal dari suatu tegakan (Harja \& vincent, 2008). Petak ukur yang diambil berupa petak ukur permanen. Data-data pengamatan yang diperoleh dianalisis spasial antar individu dalam plot pengamatan dengan menggunakan program SExI-FS (Spatially Explicit Individual-based Forest Simulator) versi 2.1.0. Program ini mensimulasikan interaksi antar individu pohon dalam suatu ekosistem hutan.

Data yang dibutuhkan untuk keperluan tersebut antara lain:

- Posisi pohon di dalam plot

- Jenis Pohon

- Diameter setinggi 1,3 m dari permukaan tanah

- Tinggi pohon

- Tinggi batang bebas cabang

- Tinggi tajuk

- $\quad$ Lebar tajuk 4 sisi, diambil seperti pada Gambar 3.
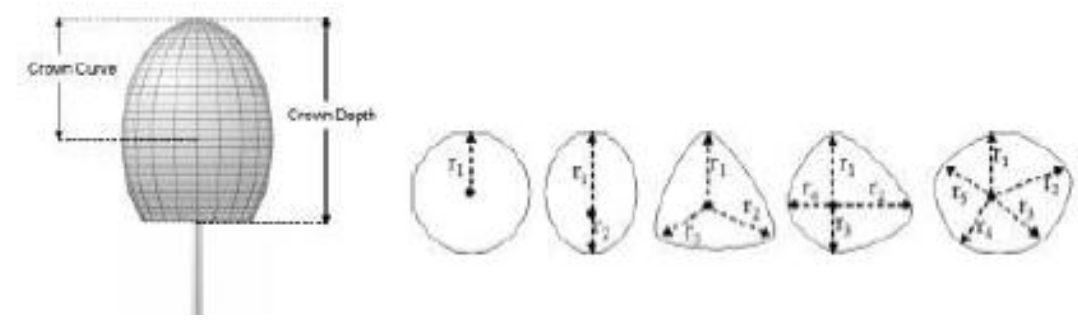

Sumber: Harja \& vincent (2008)

Gambar 3. Cara mengukur tajuk vertikal dan horisontal

\section{Hasil dan Pembahasan}

\section{Analisis Vegetasi}

Hasil penelitian ini menunjukkan bahwa terdapat 122 jenis yang terdiri dari 31 famili, dengan nilai INP tertinggi adalah Pterospermum javanicum $(21,87)$. Jenis ini juga merupakan jenis yang memiliki kerapatan relatif $(7,26)$ dan frekuensi relatif tertinggi $(4,66)$, sedangkan Shorea gusio merupakan jenis dengan Dominansi relatif tertinggi $(11,68)$. Gambaran hasil penelitian tersebut dijabarkan pada Gambar 4, 5, 6, dan 7. 


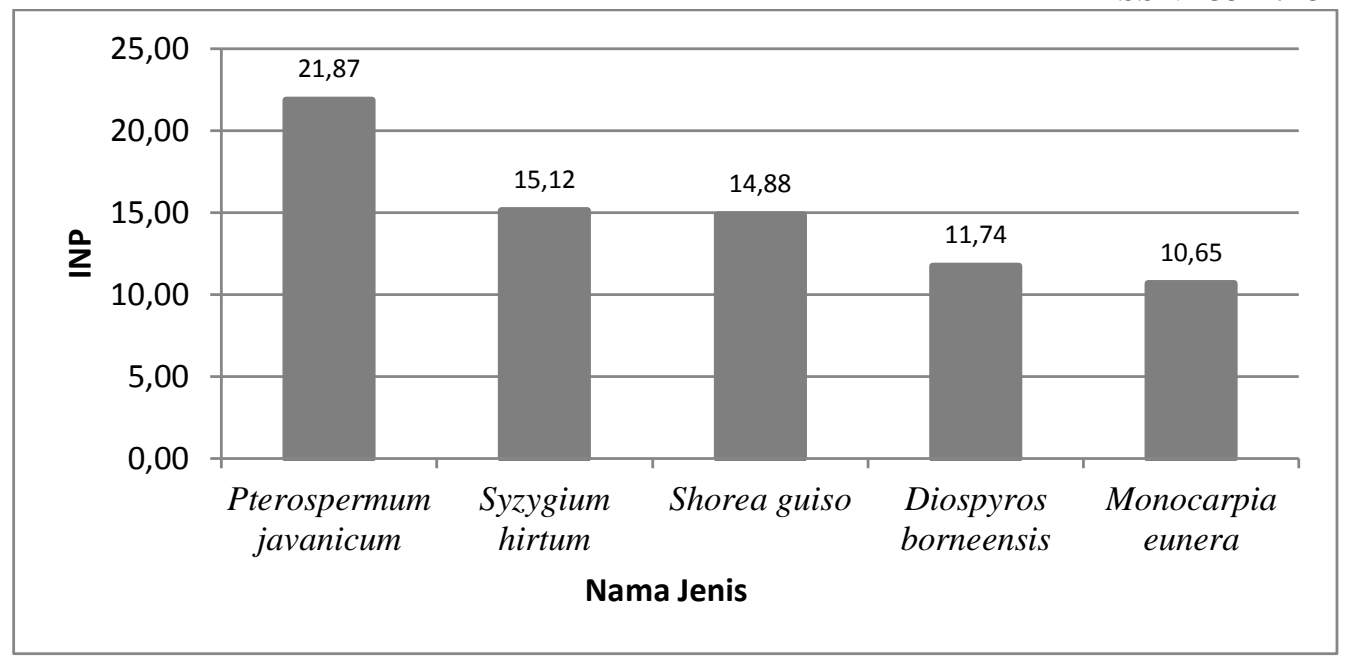

Gambar 4. Indeks nilai penting 5 jenis tertinggi

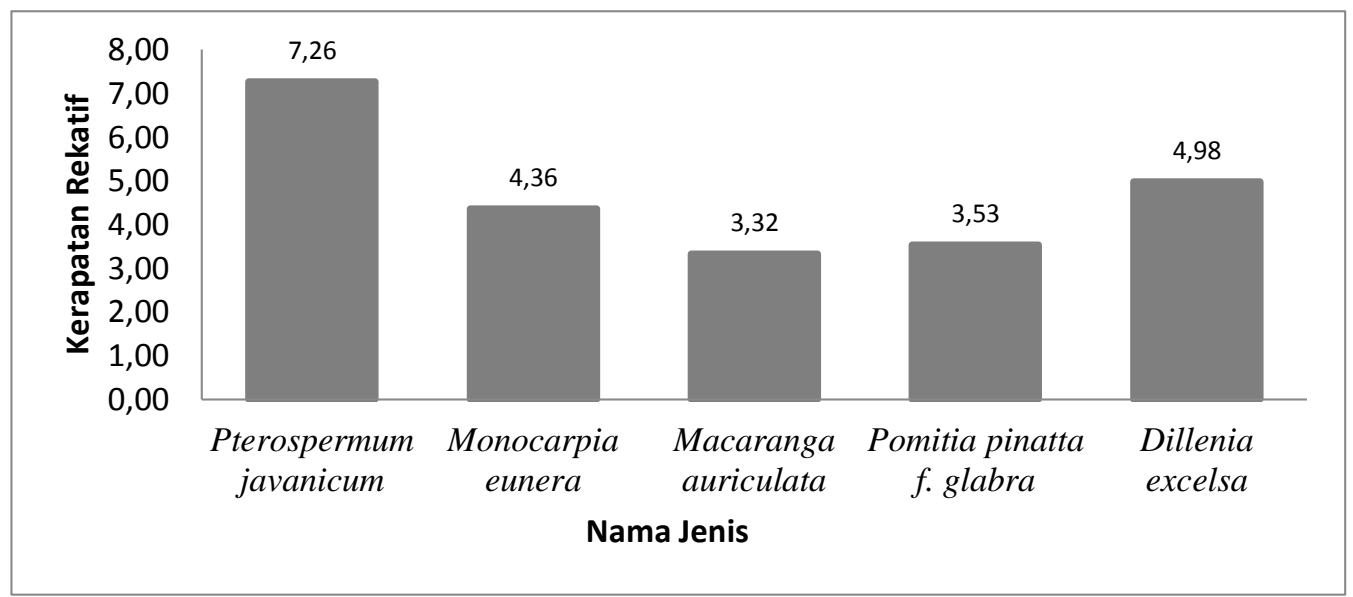

Gambar 5. Kerapatan relatif 5 jenis tertinggi

Berdasarkan Gambar 4 jenis yang memiliki INP tertinggi adalah Pterospermum javanicum artinya jenis ini memiliki fungsi dan peranan yang penting dalam kawasan tersebut. Kochummen (1972) menyatakan bahwa jenis-jenis dari genus Pterospermum merupakan jenis-jenis yang mudah tumbuh dan pada umumnya mengisi rumpang-rumpang yang terdapat pada wilayah hutan yang terbuka. Berdasarkan Gambar 5 yang memiliki nilai kerapatan tertinggi adalah Pterospermum javanicum, artinya jenis ini dari segi jumlah individunya lebih banyak dalam satuan luas kawasan tersebut dibandingkan jumlah individu yang lainnya. Pterospermum javanicum dikenal dengan nama bayur, pada umumnya dapat tumbuh pada tanah yang basah maupun kering, dengan kondisi iklim basah yang dapat ditemukan tersebar di Pulau Kalimantan dan banyak wilayah Indonesia lainnya (Martawijaya dkk., 1989). ITTO (2019) menyatakan bahwa Bayur banyak ditemukan dihutan primer dan sekunder. Hashimoto dkk. (2004) menyatakan bahwa bayur termasuk ke dalam jenis pioner, termasuk yang mudah tumbuh dan cepat besar. Hal ini menunjukkan bahwa kawasan hutan karst Temeang pernah mengalami kerusakan sehingga memunculkan jenis pioner dan jenis yang cepat tumbuh, seperti bayur. 
Adapun jenis yang memiliki dominansi tertinggi (Gambar 6) adalah Shorea guiso, jenis ini walaupun jumlahnya sedikit tetapi memiliki diameter yang besar-besar, hal inilah yang menjadikan nilai dominansinya lebih besar dibandingkan dengan jenis yang lainnya, Shorea gusio menurut Khou dkk. (2017) selain ditemukan di daerah pantai dan pesisir, ditemukan juga di daerah berkapur. Jenis ini termasuk dalam kategori rawan (vulnerable) dalan IUCN Redlist versi 3.1 yang diterbitkan pada tahun 2017.

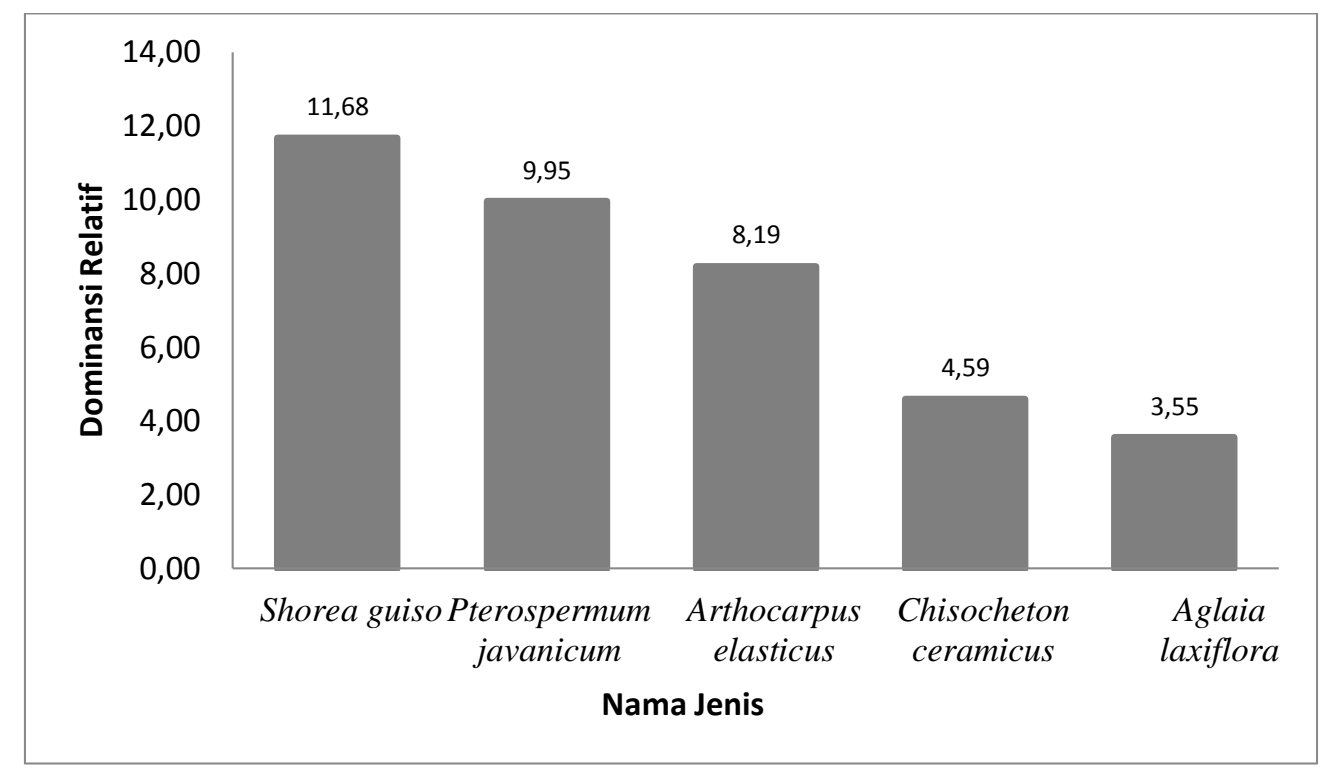

Gambar 6. Dominansi Relatif 5 jenis Tertinggi.

Frekuensi relatif adalah banyaknya jumlah plot yang ditemukan suatu jenis, hal ini berbeda dengan kerapatan, kerapatan merupakan jumlah individu, secara visual frekuensi relative disajikan pada gambar berikut ini.

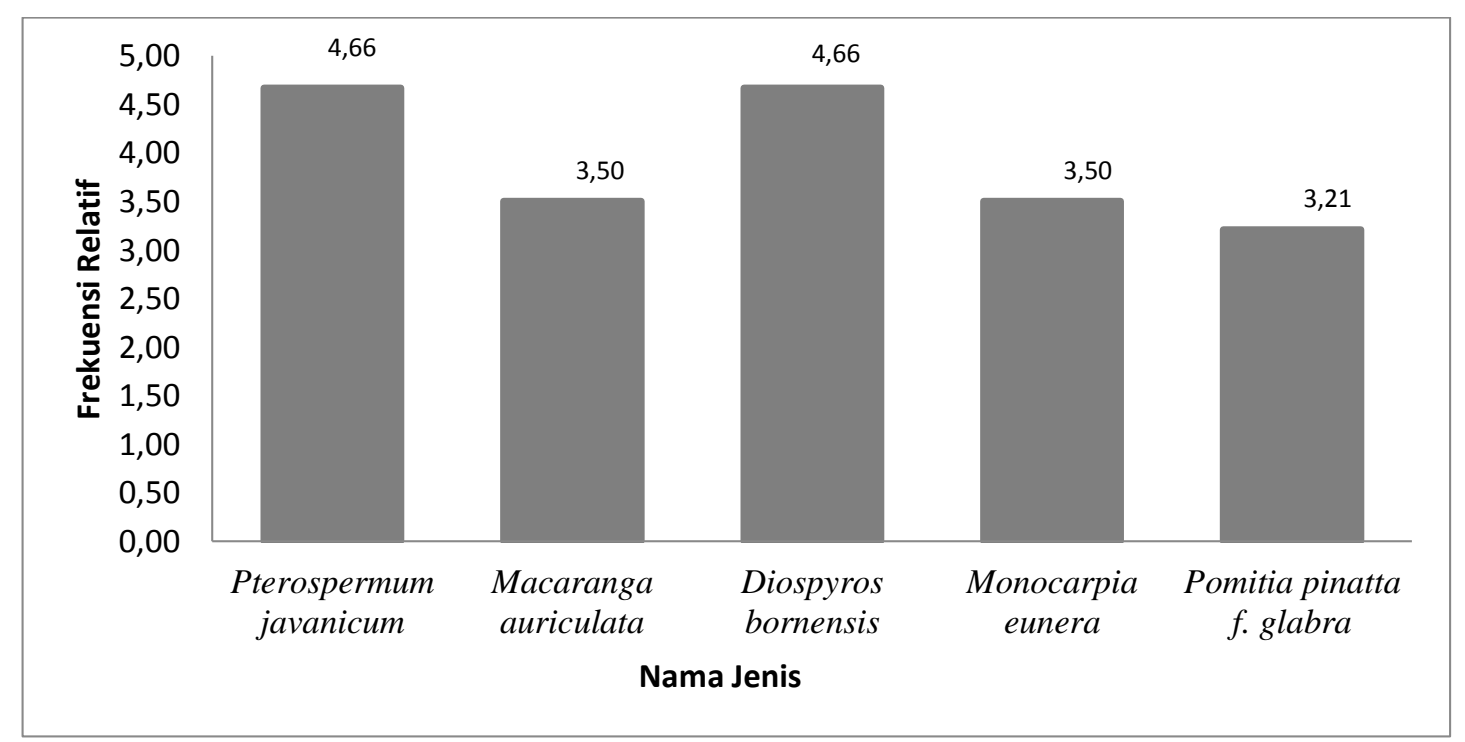

Gambar 7. Frekuensi Relatif 5 jenis Tertinggi

Frekuensi relatif adalah banyaknya jumlah plot yang ditemukan suatu jenis, hal ini berbeda dengan kerapatan, yang mana kerapatan merupakan jumlah individu. Secara 
visual frekuensi relatif disajikan pada Gambar 7. Berdasarkan Gambar 7 ada dua jenis yang memiliki nilai tertinggi yaitu Pterospermum javanicum dan Diospyros borneensis. Pterospermum javanicum sendiri merupakan jenis yang tumbuh baik pada hutan primer dan sekunder, serta merupakan jenis yang mudah tumbuh (Martawijaya dkk., 1989). Diospyros borneensis sendiri dapat tumbuh pada hutan dataran rendah, dan terkadang pada daerah yang berkapur (Alonzo, 1997), serta sering ditemukan pada hutan dipterokarpa campuran ( $\mathrm{Ng}, 2002)$. Diospyros borneensis dapat menghasilkan buah yang dapat di makan (Wahyuni, 2017), baik oleh manusia ataupun binatang, yang membantu persebaran biji. Sedangkan, Pterospermum javanicum memiliki biji yang bersayap (Argent dkk. 1987) yang dapat membantu persebarannya.

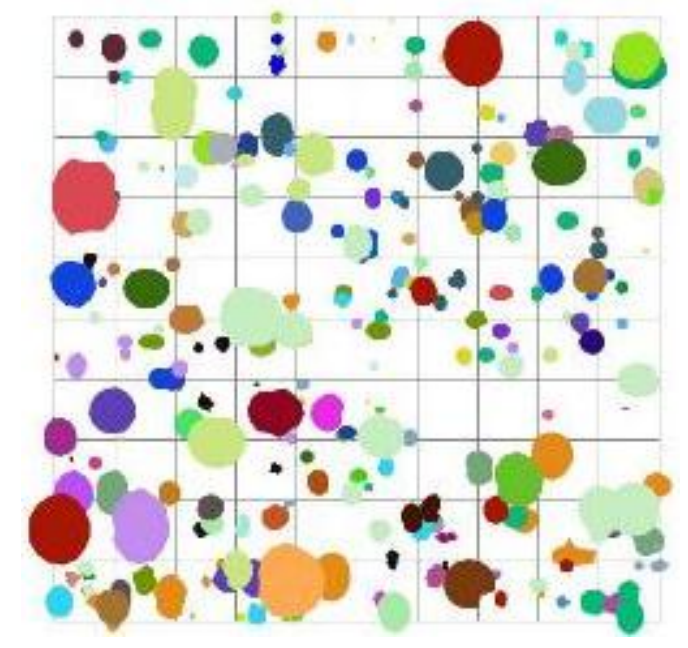

Gambar 8. Tutupan tajuk tumbuhan di plot penelitian

\section{Struktur Tegakan}

Profil tumbuhan merupakan gambaran kondisi dan posisi tumbuhan di plot penelitian adapun gambarannya secara visual yang dibuat dengan menggunakan program SExI-FS disajikan pada Gambar 8. Pada gambar tersebut terlihat tutupan tajuknya masih sangat jarang. Indriyanto (2006) mengemukakan bahwa Individu dalam suatu populasi secara intern dapat terdistribusi dalam 3 pola, yaitu: acak (random), seragam (uniform), dan bergerombol (clumped). Berdasarkan Gambar 8 diatas dapat disimpulkan bahwa individuindividu yang tumbuh di Hutan Karst Temeang terdistribusi secara acak. Hal ini menunjukkan bahwa individu-individu pohon di kawasan tersebut tumbuh pada linkungan yang seragam. Riyanto dkk. (1985) menyatakan bahwa persebaran pohon yang acak dapat terjadi dikarenakan oleh kondisi lingkungan yang seragam dengan tidak adanya kecenderungan untuk berkelompok.

Gambar 9 menunjukkan bahwa hutan di kawasan Temeang tersusun atas tegakan yang relatif tidak seumur. Gambaran vertikal tersebut menunjukkan stratifikasi susunan pohon-pohon di dalam hutan Kawasan Karst Temeang. Stratifikasi hutan menurut 
Indriyanto (2006) terdiri atas Stratum A ( Tinggi tegakan $\geq 30 \mathrm{~m}$ ), stratum B (tinggi tegakan 20-30 m), stratum C (tinggi tegakan 4-20 m) dan stratum D (tinggi tegakan 1-4 m). Sedangkan menurut Rehulina, dkk. (2014) stratifikasi atau pelapisan tajuk merupakan susunan pohon secara vertikal di dalam ekosistem hutan. Lapisan-lapisan ini dibedakan atas lapisan tajuk atas ( $A$ dan $B$ ) dan lapisan bawah (C dan D). Lapisan A dan B merupakan lapisan yang terdiri pohon-pohon. Lapisan $C$ dan $D$ adalah lapisan yang terdiri atas semak dan penutup tanah. Berdasarkan keterangan di atas, dapat disimpulkan bahwa sebagian besar pohon di Kawasan Karst Temeang menempati stratum B hingga Stratum D, atau memilik tajuk yang menyebar dari lapisan bawah hingga lapisan atas.

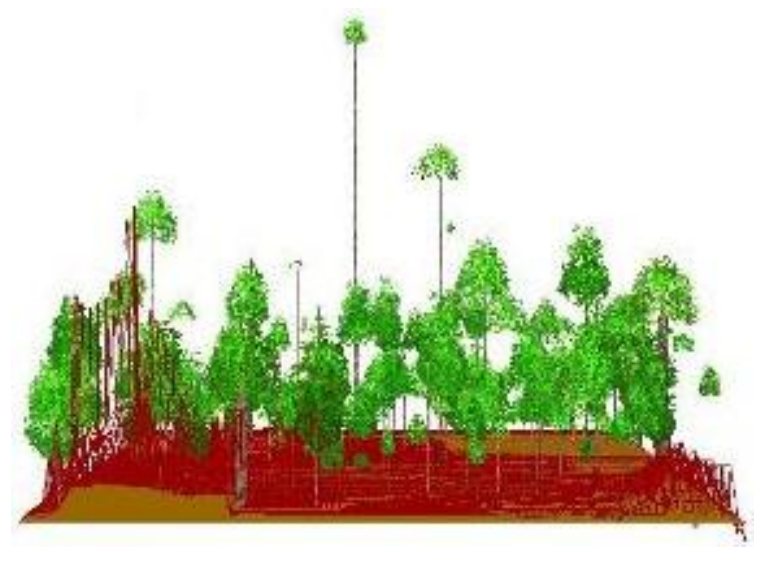

(a)

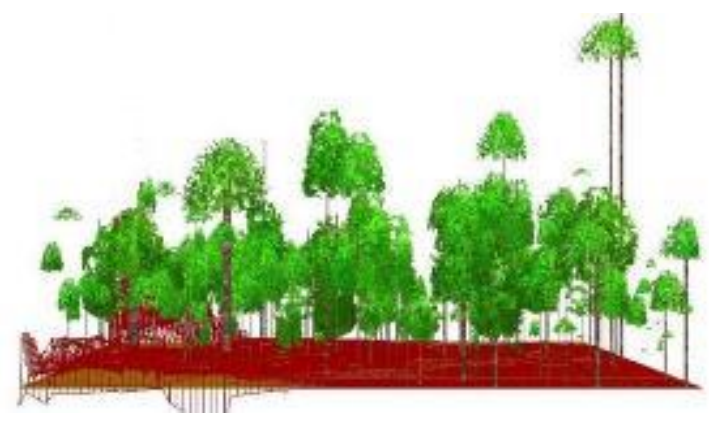

(b)

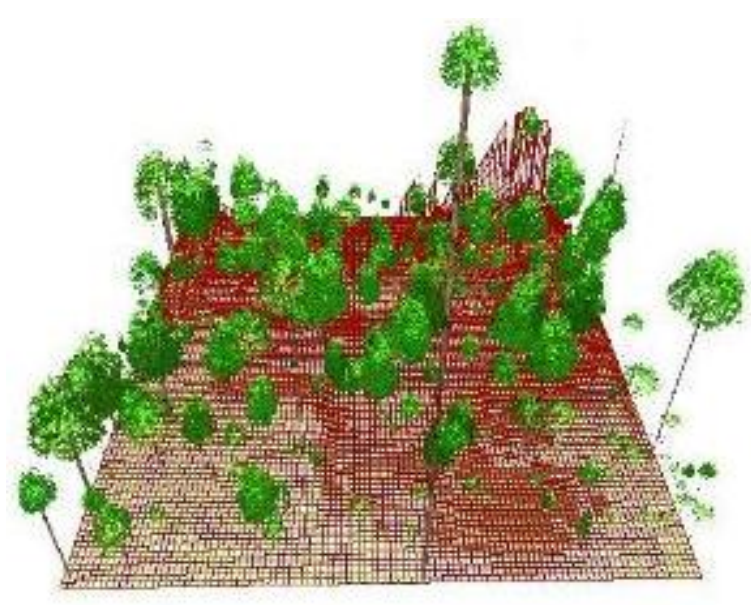

(c)

Gambar 9. Profil tiga dimensi tumbuhan di plot penelitian: (a) tampak depan; (b) tampak belakang; (c) tampak atas.

\section{$4 \quad$ Kesimpulan}

Distribusi pohon-pohon hutan di Kawasan Hutan Karst Temeang tersusun secara acak dengan lapisan tajuk yang berlapis dari lapisan bawah hingga lapisan atas. Adanya 
bagian-bagian tajuk yang masih terbuka menunjukkan bahwa perlu adanya campur tangan dari pengelola kawasan untuk mempercepat suksesi. Percepatan suksesi dapat memanfaatkan jenis bayur (Pterospermum javanicum) yang merupakan jenis dengan tingkat kehadiran dan dominansi tertinggi dan tumbuh alami pada lokasi tersebut. Bayur merupakan jenis pioner yang berperan untuk mengisi bagian-bagian kosong pada kawasan tersebut. Percepatan suksesi dapat memanfaatkan perbanyakan secara alami maupun buatan sesuai dengan tujuan peruntukan kawasan hutan pada masa mendatang.

\section{Daftar Pustaka}

Addelinetina, R. R., Dewantara, I., \& Manurung, T. F. (2019) Keterbukaan Tajuk Akibat Kegiatan Pemanenan Dengan Teknik Reduced Impact Logging Dalam Pengelolaan Hutan Alam (Studi Kasus Pada Petak Tebangan L37 RKT 2015 IUPHHK-HA PT. Batasan Camp Tontang). Jurnal Hutan Lestari, 7(3).

Adji, T. N., \& Haryono, E. (2017). Kawasan Karst dan Prospek Pengembangannya Di Indonesia. https://doi.org/10.31227/osf.io/ykt3f

Alonzo, D. Z. (1997). Diospyros L. Dalam Lemmens, R. H. M. J., Soerianegara, I., \& Wong, W. C. (eds.). Plant Resources of South-East Asia: No. 5 (2). Bogor: Prosea. hal: 185

Argent, G., A. Saridan, E.J.F. Campbell, \& P. Wilkie. (1987). Manual of the Larger and More Important Non Dipterocarp Trees of Central Kalimantan, Indonesia, vol. (2). Samarinda: Forest Research Institute.

Cahyadi, A. (2017). Pengelolaan Kawasan Karst dan Peranannya dalam Siklus Karbon di Indonesia. https://doi.org/10.31227/osf.io/8gh6d

Harja, D. and Vincént, G. (2008). Spatially Explicit Individual-based Forest Simulator - User Guide and Software. World Agroforestry Centre (ICRAF) and Institut de Recherche pour le Développement (IRD).

Haryono, E., \& Adji, T. N. (2017). Geomorfologi dan Hidrologi Karst. https://doi.org/10.31227/osf.io/7jtgx

Hashimoto, T., Tange, T., Masumori, M., Yagi, H., Sasaki, S., \& Kojima, K. (2004). Allometric equations for pioneer tree species and estimation of the aboveground biomass of a tropical secondary forest in East Kalimantan. Tropics, 14(1), 123-130.

Indriyanto. (2006). Ekologi Hutan. Jakarta: PT Bumi Aksara.

ITTO. (2019, Oktober 30). Bayur (Pterospermum javanicum). Diambil kembali dari ITTO Lesser Used Species: http://www.tropicaltimber.info/specie/bayur-pterospermumjavanicum/

Khou, E., Luu, H.T., Pooma, R., Newman, M.F. \& Barstow, M. (2017). Shorea guiso. The IUCN Red List of Threatened Species 2017: e.T33114A2832842. http://dx.doi.org/10.2305/IUCN.UK.2017-3.RLTS.T33114A2832842.en.

Downloaded on 10 September 2019.

Kochummen, K. M. (1972). Sterculiaceae. Dalam T. C. Whitmore, (ed.), Tree flora of Malaya, vol. 2, 353-382. Longman.

Martawijaya, A., Kartasujana, I., Mandang, Y. I., Prawira, S. A., \& Kadir, K. (1989). Atlas Kayu Indonesia jilid II. Badan Litbang Kehutanan Indonesia. Bogor.

Muller-Dombois, D. \& Ellenbeg, H. (1974). Aim and Methods of Vegetation Ecology. New York:John Willey and Sons. 
ISSN 2354-7251 (print)

Ng, F.S.P. (2002). Ebenaceae. Dalam Tree Flora of Sabah and Sarawak, volume 4. Soepadmo, E., Saw, L. G., \& Chung, R. C. K. (eds). Forest Research Institute Malaysia, Sabah Forestry Department, and Sarawak Forestry Department, Ampang Press Sdn. Bhd., Kuala Lumpur, Malaysia. hal: 29-100.

Rehulina, R., Purwoko, A., \& Latifah, S. (2014). Komposisi dan Stratifikasi Vegetasi Pohon di Hutan Pendidikan Universitas Sumatera Utara, Tongkoh, Kabupaten Karo, Provinsi Sumatera Utara. Peronema Forestry Science Journal, 3(2).

Riyanto, B. N., Palenewan, H. J., Suwondo, D., Jan, R., \& Petrus, K. M. (1985). Ekologi Dasar 2. Ujung pandang: Badan Kerjasama perguruan tinggi negeri Indonesia bagian timur.

Susanto, H. (2016). Potret dan Rencana Pengelolaan Ekosistem Karst. Balikpapan: Pusat Pengendalian Pembangunan Ekoregion Kalimantan Kementerian Lingkungan Hidup dan Kehutanan.

Wahyuni, S., \& Kartikawati, S. M. (2017) Identifikasi Pohon Penghasil Buah Pada Kawasan Hutan Lindung Gunung Pemancing-Gunung Ambawang Bukit Bendera Kecamatan Teluk Pakedai Kabupaten Kubu Raya. Jurnal Hutan Lestari, 5(2). 